
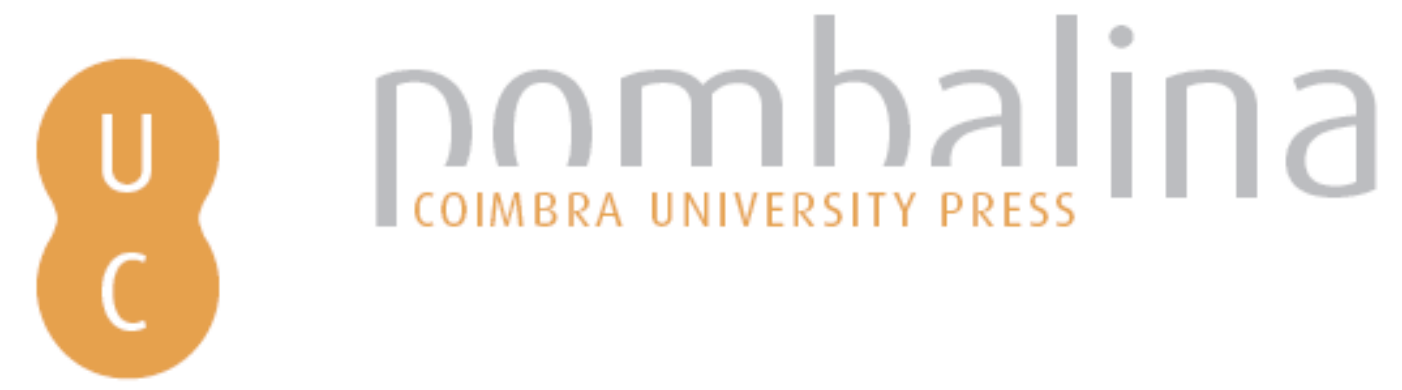

\title{
A escola em territórios de baixa densidade: proposta para a construção de uma matriz de reorganização da rede escolar
}

\author{
Autor(es): $\quad$ Cordeiro, A. M. Rochette \\ Publicado por: Imprensa da Universidade de Coimbra \\ URL \\ persistente: $\quad$ URI:http://hdl.handle.net/10316.2/43492 \\ DOI: $\quad$ DOI:https://doi.org/10.14195/978-989-26-1343-7_22 \\ Accessed : $\quad$ 26-Apr-2023 12:41:30
}

A navegação consulta e descarregamento dos títulos inseridos nas Bibliotecas Digitais UC Digitalis, UC Pombalina e UC Impactum, pressupõem a aceitação plena e sem reservas dos Termos e Condições de Uso destas Bibliotecas Digitais, disponíveis em https://digitalis.uc.pt/pt-pt/termos.

Conforme exposto nos referidos Termos e Condições de Uso, o descarregamento de títulos de acesso restrito requer uma licença válida de autorização devendo o utilizador aceder ao(s) documento(s) a partir de um endereço de IP da instituição detentora da supramencionada licença.

Ao utilizador é apenas permitido o descarregamento para uso pessoal, pelo que o emprego do(s) título(s) descarregado(s) para outro fim, designadamente comercial, carece de autorização do respetivo autor ou editor da obra.

Na medida em que todas as obras da UC Digitalis se encontram protegidas pelo Código do Direito de Autor e Direitos Conexos e demais legislação aplicável, toda a cópia, parcial ou total, deste documento, nos casos em que é legalmente admitida, deverá conter ou fazer-se acompanhar por este aviso.

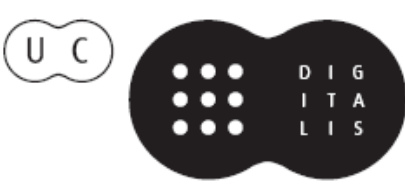




\section{FERNANDA CRAVIDÃO}

\section{IÚCIO CUNHA}

PAULA SANTANA

\section{NORBERTOSANTOS}

(ORG.)

\section{ESPAÇOS E TEMPOS EM GEOGRAFIA}

HOMENAGEM A ANTÓNIO GAMA

IMPRENISA DÁ UNIVERSIDADE DE COIMBRA COIMBRA UNIVERSITY PRESS

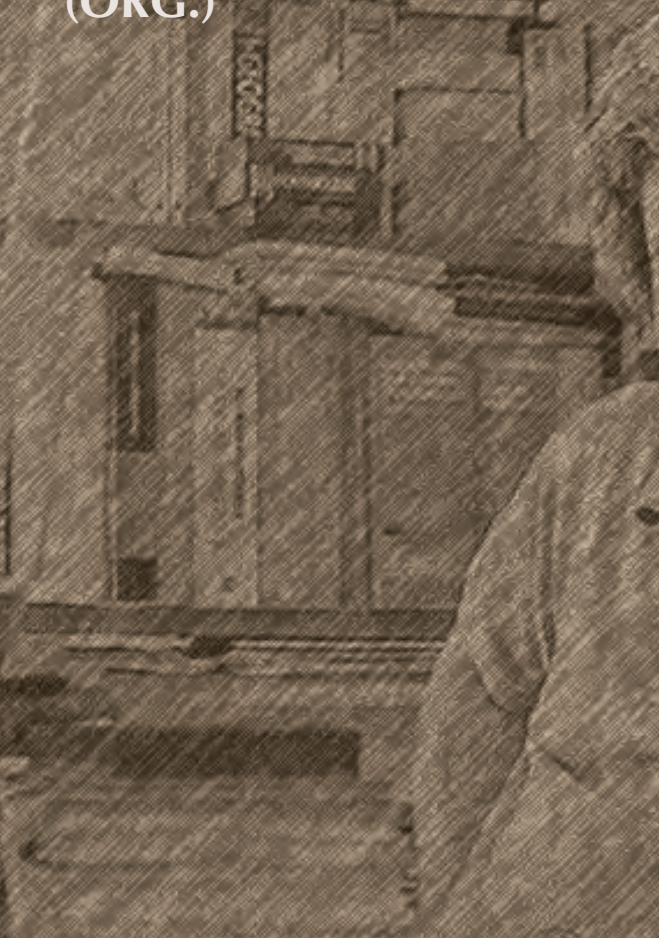




\title{
A ESCOLA EM TERRITÓRIOS DE BAIXA DENSIDADE. PROPOSTA PARA A CONSTRUÇÁO DE UMA MATRIZ DE REORGANIZAÇÁO DA REDE ESCOLAR
}

\author{
A. M. Rochette Cordeiro/rochettecordeiro@fl.uc.pt \\ Departamento de Geografia e Turismo \\ da Faculdade de Letras da Universidade de Coimbra \\ e Centro de Estudos Interdisciplinares do Século XX - CEIS 20
}

\section{Contextualização da problemática}

Com a expulsão da Companhia de Jesus na $2 .^{a}$ metade do século xviı e a consequente reforma do ensino protagonizada pelo Marquês de Pombal (Ministro do rei D. José), o Estado passou a deter a responsabilidade pela educaçáo em Portugal. Desde esse momento, o sistema educativo português tem apresentado um carácter centralizado, passando a rede escolar por um longo caminho em que as escolas ocupavam maioritariamente edifícios devolutos preexistentes. O Estado respondeu a partir de então, e durante mais de século e meio, através de um processo reativo na definição do parque escolar português, muito em função dos edifícios associados à expulsão das ordens religiosas nos séculos XVIII e XIX - conventos e antigos colégios religiosos -, situação que se prolongou mesmo por toda a 1. ${ }^{a}$ República (Cordeiro, 2014). As sucessivas reformas, e no que se refere às infraestruturas, não foram capazes de ultrapassar as meras referências às rendas das casas para escolas e professores, o fornecimento de mobiliário e de material de apoio (Alcoforado et al., 2011). 
Este caminho (entre muitas outras explicaçóes) levou Portugal a chegar ao final do primeiro período republicano com indicadores educativos e escolares exageradamente baixos e com uma rede escolar cujos edifícios da responsabilidade das Câmaras Municipais, sem plano coordenador, eram distribuídos por casas particulares e antigos edifícios religiosos.

Neste contexto, o primeiro verdadeiro momento de uma visão de planeamento para a rede escolar em Portugal acontece no início da década de 40 do século xx (na vigência de um Governo do Estado Novo), com o desenvolvimento de uma agenda bem planeada de edificação de escolas. O designado "Plano dos Centenários" pretendia a criação de uma rede escolar de índole nacional com o objetivo fundamental de diminuir o enorme atraso educacional que se observava relativamente aos demais países europeus. Este plano previa o número, a localização e o tipo de escolas a construir em todo o país procurando-se, pela primeira vez, enfrentar a necessidade de edificar um parque escolar adequado à população e às características demográficas e geográficas do país (Martins et al., 2011). Através do Despacho do Conselho de Ministros de 15 de Julho de 1941, o Governo enunciava a construção de 6060 edifícios, com 12500 salas, numa tipologia que não poderia ultrapassar as quatro salas por edifício $(74 \%$ teriam apenas uma sala) e quarenta alunos por professor, com uma localização geográfica que não tornasse necessário a qualquer aluno andar mais de três quilómetros (Alcoforado et al., 2011).

A localização e caracterização dos edifícios permitia (e ainda hoje permite) identificá-los como construçóes com identidade própria - maioritariamente com orientação a nascente, localizados num terreno que não deveria apresentar uma área inferior a $2000 \mathrm{~m}^{2}$ e com facilidade de abastecimento de água ${ }^{1}$. Neste contexto, foram construídas milhares de escolas que pretendiam ser a base física para ultrapassar o grande atraso que o país mostrava em termos educativos onde, no início do seu processo de implementação, exibia números brutais de

\footnotetext{
1 Assumidos através de uma adaptação funcional dos projetos-tipo regionalizados dos Arquitetos Raul Lino e Rogério Azevedo, este edificado acabou por se tornar em assinaláveis referências das comunidades onde foi construído (Alcoforado et al., 2011).
} 
analfabetismo, apresentando em 1950 valores globais nacionais na ordem dos $40 \%$ (41,7\%), observando-se mesmo uma percentagem de $24,5 \%$ nos jovens com idades compreendidas entre os 10 e os 14 anos (Mata, 2014).

A rede escolar de proximidade desenhada nos anos 40 , muito pelo facto de as acessibilidades se apresentarem como extremamente deficitárias, levou a que no Portugal rural fossem disseminados edifícios pelos pequenos lugares. Contudo com a crise emigratória dos anos 60/70, estes territórios foram-se desertificando levando a um consequente processo de transformação de amplos setores do país rural onde o envelhecimento passou a ser uma das "marcas" territoriais. No decorrer das últimas décadas do século $\mathrm{xx}$, fruto dessas profundas transformaçôes demográficas, mas também por via das alteraçôes socioeconómicas e de mobilidades que Portugal sofreu, a rede escolar passou a debater-se com graves desequilíbrios entre a oferta e a procura, facto que se traduziu num enorme paradoxo: alunos a menos e escolas a mais, em particular nestes territórios de baixa densidade (Cordeiro, 2014).

Em função destas transformaçóes e a constatação da realidade de uma significativa diminuição de alunos nas escolas, foi assinado nos finais dos anos 80 um acordo com a União Europeia no qual era equacionado o encerramento das escolas de $1 .^{\circ}$ ciclo do ensino básico $\left(1 .{ }^{\circ} \mathrm{CEB}\right)$ que apresentassem um número inferior a 21 alunos. Porém, só a partir de 2003, com a elaboraçáo das cartas educativas de responsabilidade autárquica, se iniciou uma nova fase de planeamento da rede escolar pública portuguesa do $1 .{ }^{\circ} \mathrm{CEB}$, tendo estas ficado marcadas pela afirmação do seu carácter prospetivo, pelo protagonismo da dimensão local na construçáo das soluções, pela diversidade e pela pluralidade de propostas de reorganização e de distribuição territorial, apresentando uma lógica algo oposta à do centralismo estatal do Plano dos Centenários (Cordeiro e Martins, 2013; Cordeiro et al., 2014).

Todavia, a temática da "reorganização da rede escolar", nesta última década, só muito raramente reuniu consenso entre os diferentes investigadores e atores, levando a importantes reflexôes acerca do encerramento destas escolas, no essencial pelos reflexos negativos que estes fechos apresentaram nas comunidades locais, em particular no mundo rural português. 
Nos vários documentos de suporte legal às medidas de encerramento de estabelecimentos de ensino preconizadas pela Tutela, assumia-se que as escolas com um número inferior a 21 alunos náo eram propícias ao sucesso escolar, mencionando-se amiúde que existiria uma relação direta entre a dimensão das escolas e o sucesso escolar. A lógica centrava-se no facto de, nestes estabelecimentos de ensino, os alunos e professores terem menos hipóteses de progredir na sua formação e no seu desenvolvimento, seja pelas diminutas oportunidades de aprendizagem conjunta, seja pelos trabalhos de grupo, convívio social e troca de experiências, ao invés do que é assumido para com os alunos dos estabelecimentos de maior dimensão.

Neste contexto, assistiu-se em Portugal, na última década, ao encerramento de largas centenas de escolas (em particular do 1. ${ }^{\circ} \mathrm{CEB}$ ), fenómeno constatado particularmente nos territórios de baixa densidade (Cordeiro, 2014). Porém, não pode deixar de ser referida a realidade das questôes relacionadas com a distribuiçáo dos equipamentos educativos onde náo é mais do que uma das diferentes facetas do universo das preocupaçóes que englobam as atividades económicas no meio rural, as estratégias de ocupação do território ou a preservação de espaços sociais e culturais ameaçados pelos valores dominantes (Azevedo, 1996). A premência da procura de soluçôes para a coesão territorial de amplos setores do Portugal rural tem levado à demanda de novos paradigmas nos quais a educaçáo deve ser assumida como um dos seus principais pilares.

$\mathrm{Na}$ realidade, e resultado da desertificação e envelhecimento que caracterizam estes territórios, as suas escolas, inseridas em comunidades isoladas, acabam por ter poucos alunos e poucos recursos. Cada uma destas escolas insere-se numa aldeia ou numa freguesia distante geograficamente das escolas de maior dimensão, facto que pode promover um isolamento pedagógico e a não obtenção de resultados táo bons quanto os alunos destas (Matthews et al., 2009).

Há, contudo, referências bibliográficas e argumentos que defendem a manutenção destas escolas de territórios de baixa densidade, tendo em conta que se apresentam como meios vivos para a criança, fazendo parte do seu 
ambiente diário, permitindo ao professor conhecer bem a criança no seio da sua família, num certo contexto sociocultural, com o seu passado e com a projeção do futuro mais ou menos expressa pelos pais, sendo as escolas, em meio rural um elemento essencial da identidade comunitária (Champollion, 2011; Machado, 2013).

Foi neste quadro de grande diversidade de opinióes (e julga-se que com mais de uma década de atraso) que se propóe o revisitar sobre as virtualidades e as desvantagens de manutenção de escolas em territórios de baixa densidade (rurais e de montanha). O presente texto deve ser assumido, no essencial, como ponto de partida sobre a discussão do papel da escola na construção de uma coesão territorial que é absolutamente imperiosa para amplos setores do interior de Portugal, sobretudo no contexto das políticas públicas de educação. Assim, e face à solicitação de diferentes atores locais (nomeadamente autarcas), foi desenvolvida uma matriz de reorganização de rede escolar em territórios de baixa densidade, a qual teve como objetivo fulcral criar mecanismos para o repensar do papel da escola nesses territórios (Cordeiro e Gama, coords., 2015).

\section{A Escola rural e de montanha no $1 .^{\circ}$ quartel do século XXI}

Os espaços de baixa densidade podem, numa análise global sobre os diferentes mosaicos de um Portugal cada vez mais heterogéneo, apresentar matizes muito variadas, mostrando assim, uma segmentação: os de carácter rural (em continuidade geográfica); os de montanha (onde a movimentação orográfica, quer em montanha, quer nos vales mais profundos levam à existência de declives elevados); ou mesmo os periurbanos, os quais globalmente, e mesmo que apresentando problemas idênticos, integram contextos muito diferenciados. Estes têm vindo a apresentar-se como territórios onde as características socioeconómicas e culturais vão ter algum peso na definição dos percursos escolares dos alunos, fazendo com que a ruralidade surja, ainda hoje, como ónus. 
As características territoriais de base destas escolas - envelhecimento, desertificaçáo, poucos recursos - refletem-se numa populaçáo escolar reduzida criando, de acordo com a tutela, obstáculos à modernizaçáo e reorganizaçáo da escola do $1^{\circ}$ Ciclo do Ensino Básico. Anos antes, Canário referia já que "a escola em meio rural poderá estar a induzir uma iniciação à escola que náo prepara as crianças para a inevitabilidade da vida num mundo urbano" (Canário, 2000). Assim, a escola em territórios de baixa densidade poderá, no entender de alguns autores, promover um isolamento pedagógico, estando as crianças isoladas dos restantes colegas assim como os próprios professores (Canário, 2000; Formosinho, 1998; cfr. Machado, 2013). Nesse sentido, parece existir uma tendência dos alunos oriundos de escolas pequenas para a não obtençáo de resultados táo bons quanto os alunos de escolas de maior dimensão, mesmo que estes resultados não sejam visíveis no imediato (Matthews et al., 2009; Cordeiro e Alcoforado, coord., 2015).

Contudo, e muito na linha de inúmeros estudos realizados em regiōes e países da Europa do Sul com territórios e caraterísticas demográficas idênticas (França e Espanha), observam-se também argumentos que defendem a manutençâo destas escolas (Alpe, 2008; Boix, 2008; Champollion, 2008; 2011). É, portanto, nessa linha de pensamento que sobressaem os fatores positivos destas escolas permitindo utilizar os conhecimentos existentes e desenvolver uma sinergia entre toda a comunidade educativa utilizando a riqueza do espaço envolvente tais como a história, as paisagens, a vida cívica em parceria com projetos elaborados e desenvolvidos com a autarquia, as associaçóes e os habitantes, possibilitando às crianças passar do meio familiar para a escola sem rutura do contexto familiar, favorecendo a construção das suas referências e a sua abertura ao exterior (Jean, 1995; Champollion, 2008)

As escolas rurais podem, assim, assumir uma verdadeira riqueza na medida em que permitem uma maior socialização das crianças ao integrá-las no coletivo devido à qualidade das relaçôes entre crianças, pais e professores, favorecendo as afinidades entre indivíduos e facilitando uma construção do tecido social (Jean, 1995).

Neste contexto dialético entre os defensores da manutenção ou do encerramento das escolas de territórios rurais e de montanha, as questóes pedagógicas 
ganham ainda contornos mais extremados quando associadas à impossibilidade de manter turmas homogéneas em escolas com número diminuto de crianças, facto que tem motivado a discussão à volta da existência de turmas constituídas por mais de um nível de ensino ${ }^{2}$.

A diversidade de alunos, dentro de uma turma, acarreta uma tarefa muito mais exigente para os professores surgindo, naturalmente associada ao receio de não conseguirem apoiar os alunos com maiores dificuldades de aprendizagem, assim como o de não poderem dar a devida atenção aos mais desenvolvidos. Nos casos em que a heterogeneidade é bastante elevada acresce a dificuldade de atender a todos os alunos, sobretudo se tivermos em conta que os programas são, muitas vezes, desajustados e demasiado longos. Estes fatores podem levar à existência de situaçôes em que os professores sentem angústia por não conseguirem responder, com o seu trabalho, ao nível dos critérios de exigência, do seu desejo de atender e de desenvolver todos os tipos de alunos que têm à sua frente (Cortesão, 1998; cfr. Machado, 2013).

No campo da investigação, também nesta temática não existe amplo consenso relativamente à virtualidade destas turmas, ainda hoje muito numerosas nos meios rurais e de montanha. Parece ser evidente que em Portugal subsiste uma insuficiência de estudos que se centram em turmas com diferentes anos de escolaridade. No estudo levado a cabo por Fátima Machado é feita uma associação ao termo multi-grade (OCDE, 1989; cfr. Machado, 2013), cuja definição refere o envolvimento de dois ou mais anos de escolaridade na mesma sala de aula, tendo os professores de lecionar mais do que um currículo em simultâneo ${ }^{3}$. Para o nosso país, que integrou a amostra desse estudo, é mencionado que estas turmas surgem por força das circunstâncias e não enquanto escolha,

\footnotetext{
${ }^{2}$ A legislação em vigor, relativamente à constituição das turmas, demonstra-nos que em Portugal pode existir uma grande heterogeneidade, em especial nas turmas do $1 .^{\circ}$ ciclo do ensino básico.

${ }^{3}$ No ano de 1989 foi publicado um relatório da OCDE, intitulado "As Escolas e a Qualidade", onde são referidos estudos nos quais se comprova que as escolas de pequena dimensão criam ambientes mais familiares e acolhedores, enquanto as escolas de grandes dimensóes têm outras vantagens, tais como a oferta de uma maior variedade de atividades extracurriculares (OCDE, 1989).
} 
pelo que a sua constituição é o reflexo da realidade demográfica de pequenos povoados em zonas rurais ou de montanha.

A abordagem feita por vários estudos a nível internacional sobre esta realidade torna possível recolher informaçóes onde é evocada esta dicotomia entre aspetos desfavoráveis e favoráveis à criação e permanência destas turmas. Os aspetos desfavoráveis prendem-se com o facto de os alunos só receberem atenção direta do professor durante um tempo parcial, não constituindo um contexto favorável às aprendizagens (Mingat e Ogiet, 1995). Estes resultados foram obtidos em França no ano de 1993, época em que a carta escolar nacional determinava que, sempre que possível, se organizassem turmas de um só nível (Zanten e Obin, 2008). O argumento na altura sustentava que, para além das dificuldades que estas turmas representavam para o professor, também devido à necessidade de lecionar vários níveis não constituíam um contexto pedagógico favorável porque o professor tinha de partilhar o seu tempo entre os diferentes grupos de alunos ${ }^{4}$.

Em Portugal, por via do encerramento de muitas escolas com um número inferior a 21 alunos, assistiu-se à deslocalização destes para escolas de maior dimensão e, um pouco por todo o país, propagou-se a construçáo de Centros Escolares que, de acordo com os discursos que sustentam essa medida, tenderiam a oferecer condiçóes de igualdade de oportunidades e de melhoria na qualidade de ensino. Foi portanto, baseado neste argumento, e através de um discurso de promoção do sucesso escolar, que se visou a escola de meio rural, adotando-se uma (não) estratégia, na medida em que não se criaram quaisquer planos para a resolução da situação. Tal facto, em muito tem contribuído para acentuar a desertificaçáo humana o envelhecimento exponencial da população, a ausência de alternativas de empregabilidade, entre outros factores (Ferreira e Oliveira, 2007). Em suma, com base na anterior argumentação teórica, e concomitantemente ao discurso da concentração em centros escolares, surge o

\footnotetext{
${ }^{4}$ Importa destacar que, em diversas reunióes tidas no âmbito da construção de diferentes Projetos Educativos Locais, estes argumentos foram igualmente utilizados pelos docentes que assumiam grupos com estas caraterísticas nos diferentes territórios.
} 
inevitável encerramento de centenas de escolas de 1. $\mathrm{CEB}$ em territórios de baixa densidade, o que "ajudou", em definitivo, a uma tendência crescente da desertificação populacional desses territórios 5 .

Não obstante, de novo se salienta a existência de vários estudos apresentados que validam a ideia das escolas pequenas em meio rural poderem ser vantajosas. Entre eles está o estudo levado a cabo por Sigsworth e Solstad (2001), no qual os autores referem que a estrutura social destas escolas apresenta semelhanças a uma família mais alargada na medida em que o professor tem as mesmas ou mais preocupaçóes dos seus colegas de outro tipo de escolas e, consequentemente, turmas maiores. No mesmo estudo é ainda referido poder o professor sentir-se só, cheio de dúvidas, acontecendo ainda a natural possibilidade de ter de se preocupar com questóes relativas à organização da escola. No entanto, o seu tempo na escola torna-se precioso, devendo ser aproveitado ao máximo para promover o sucesso das aprendizagens dos alunos. No mesmo estudo, sobre estas escolas de menor dimensão onde existem necessariamente turmas com vários níveis de ensino, é referido ser possível observar que as crianças se encontram diariamente em contacto com outras de diferentes idades, e que a composição da turma vai-se alterando muito lentamente de ano para ano, na medida em que os alunos mais velhos, ao terminarem o ciclo, dão entrada a alunos novos que se vão inserindo gradualmente na estrutura da turma. Nesse sentido, as relaçóes entre os alunos vão-se desenvolvendo com os da sua idade, mas também com alunos de outras idades, promovendo e desenvolvendo a noção de identidade dentro do grupo.

$\mathrm{Na}$ realidade, parece não existir um consenso relativamente ao encerramento destas escolas, embora, e no sentido da ideia de coesão territorial, não deva ser esquecido que, nos territórios onde elas se encontram inseridas, o seu encerramento traduzir-se-á, necessariamente, por consequências sociais significativas. Parece ser inquestionável que em determinados contextos (projetos educativos

\footnotetext{
${ }^{5}$ Contudo, não pode deixar de ser referido que quando tal situação se observa a dimensão do problema já se encontra no limiar de sustentabilidade demográfica sendo, por norma, a escola o último reduto resistente ao encerramento dos serviços nestes mesmos territórios.
} 
próprios, reflexão sobre as práticas pedagógicas alternativas, etc.) a escola situada em meio rural contém diferentes potencialidades de desenvolvimento de um trabalho educativo e pedagógico com grande abrangência social e comunitária. É nesta lógica de pensamento, por exemplo, que surgem as questôes relacionadas com a importância da escola para o desenvolvimento rural defendidas por Ferreira e Oliveira (2007).

Os territórios rurais apresentam, em si mesmo, um recurso fundamental na medida em que se constituem como uma reserva de espaço físico, assumindo um papel preponderante nos processos de proteção e preservação da natureza e da paisagem envolvente (Almeida, 1998). É nesse âmbito que, para a riqueza desses territórios, as escolas deverão ser cada vez menos entendidas num sentido estritamente escolar, mas, isso sim, deverão ser encaradas num contexto educativo, enquanto lugares de fomento a uma cultura comum, promovendo projetos e políticas em que seja defendida essa territorialização da escola, por forma a ver destacada a sua polivalência e a ampla oferta educativa.

Reforçando os argumentos anteriormente expressos relativamente às escolas em territórios de baixa densidade, importa refletir ainda acerca da dimensão emblemática que esta instituição possui, constituindo-se como um elemento identitário da própria comunidade. Num meio rural, a escola apresenta-se como o serviço que resta após todos os outros terem desaparecido, terem sido deslocalizados pelo Estado, ou até, alguns deles, terem mesmo falhado os seus propósitos. Independentemente das razóes que levam a esta situação, a comunidade, no seu todo, é quem sai penalizada, pelo que as ameaças à escola são uma das dimensóes do problema que mais tem afetado os territórios de baixa densidade ${ }^{6}$.

\footnotetext{
${ }^{6}$ Porém, importa ter presente que muitas destas escolas poderão vir a sofrer um encerramento natural devido à diminuição progressiva da população, nomeadamente em idade fértil, contribuindo para que simplesmente não nasçam crianças nestes territórios (Cordeiro, 2014).
} 


\section{Abordagem preliminar à construçáo de uma Matriz para reorganizaçáo de rede educativa de territórios de baixa densidade}

Se é verdade que existem territórios onde, devido às suas características demográficas, é impossível manter uma escola a exercer apenas a sua função de escolarizar crianças, também é verdade que este espaço pode ser revitalizado de modo a transformar-se num excelente meio de desenvolvimento local. Para tal, é forçosamente necessário o empenho dos autarcas e das comunidades na assunção e no reconhecimento da escola, enquanto instituição, evidenciando a criação de um serviço local, reconhecendo os novos papéis para a mesma ou, pelo menos, considerando as diferentes tarefas que ela pode assumir, lançando novos desafios e apostando noutros contributos e propostas de parcerias (Amiguinho, 2005). Ao desenvolver-se uma estratégia para a educação num determinado território - projeto educativo local - este deve ter em consideração todas estas perspetivas (Cordeiro et al., 2012; Alcoforado et al., 2014), aliás, no sentido do constatado também por Smit e Humpert (2012).

Foi no sentido do reconhecimento da importância destas escolas como fatores de desenvolvimento em territórios rurais e de montanha que o desafio de construção de uma matriz de reorganização da rede escolar, a nível municipal, foi assumido (Cordeiro e Gama, coords., 2015).

$\mathrm{Na}$ reorganização da rede escolar da primeira década do século xxi todo o enfoque, tal como tem vindo a ser salientado, se coloca no número de alunos de cada estabelecimento de ensino como premissa decisiva. Só muito ocasionalmente a análise das condicionantes naturais, demográficas e pedagógicas foram tidas em consideração nas decisôes de encerramento ou de manutenção de escolas. A morfologia dos territórios, assim como os cursos de água de maior dimensão, não assumiram papel relevante nos projetos de cartas educativas de $1 .^{a}$ geração, tornando-se por demais evidente que essas condicionantes são muitas vezes responsáveis por "fronteiras" e mesmo alguns estrangulamentos em termos de mobilidade observados nos diferentes territórios. De igual modo, só pontualmente foi analisada a rede viária (muitas vezes associada a esses mesmos constrangimentos naturais), a qual é 
responsável pela criação de debilidades nas mobilidades, nomeadamente em territórios mais acidentados.

Quanto às questôes relacionadas com as dinâmicas demográficas, por seu turno, não foram em muitas situaçôes compreendidas na sua plenitude. Neste âmbito, e a título de exemplo, observa-se preferencialmente a análise dos valores atuais e não os seus quantitativos e características futuras, as quais associadas às questôes dos fluxos diários da populaçáo escolar, deveriam fornecer diferentes cenários em termos das décadas seguintes ${ }^{7}$. Todavia, esta leitura das alteraçōes deveria ter sido integrada de igual modo no contexto alargado da evolução dos respetivos sistemas sociais, culturais, económicos e políticos dos diferentes territórios, uma vez que a situação de uma comunidade, projetada no futuro, seguramente revelará muito sobre como poderá vir a ser.

$\mathrm{Na}$ construção de uma matriz, e além dos fatores anteriormente destacados, outros existem que têm de ser integrados, nomeadamente os de índole pedagógica e da comunidade envolvente. Estes devem ser trabalhados dado considerar-se existirem múltiplas questôes que condicionam as dinâmicas das famílias e dos alunos aquando da procura de uma escola, sendo importante as suas condiçóes de aprendizagem e não somente o número de inscritos.

Assim, e de modo a organizar os critérios atendendo ao grau de influência que devem ter na análise global da tomada de decisão, é forçoso levar em linha de conta um dos cinco principais fatores escolhidos - território; demografia; dinâmicas empresariais; componentes pedagógicas; e espaço e comunidade educativa. Estes factores apresentam valores de ponderação de enorme amplitude - podem ir dos 40\% aplicados ao território, aos 5\% da dinâmica empresarial. No entanto, e desde o primeiro momento, dois elementos são assumidos como bloqueadores, obrigando desde logo à manutençáo de uma escola: uma distância-tempo que náo pode ser superior a 25 minutos e a existência de um projeto educativo de escola alternativo onde se observem propostas de práticas

\footnotetext{
7 É ainda de refletir que desenvolvendo-se as cartas educativas na segunda metade da década, os valores utilizados foram, em muitas situaçóes, os relacionados com o início da década, ou seja, os relacionados com os Censos de 2001.
} 
pedagógicas inovadoras. Por sua vez, cada um dos 23 subcritérios apresenta uma pontuação atribuída entre 1 e 5 (sendo 1 o valor mais baixo e 5 o mais alto), e em que o cálculo final é o relacionado com os dois tipos de pontuação (Figura 1).

Esta matriz integra, assim, uma análise ao nível do território (com ponderação global de 40\%), nomeadamente a "distância tempo de casa-escola", a "sinuosidade/perigosidade" e uma "Análise de Componentes Principais" (ACP). Portanto, e considerando-se que a distância e as condiçóes físicas do território em muito podem condicionar a transferência de alunos do $1^{\circ}$ Ciclo do Ensino Básico para uma escola vizinha de acolhimento, todos os subcritérios integrados neste critério, e pelos motivos anteriormente descritos, têm níveis de ponderação elevados (níveis 5 e 4).

O segundo critério é referente à análise das questôes demográficas (que apresenta ponderação global de $20 \%$ ), nomeadamente no que concerne à população escolar, às projeções demográficas e à fidelização atual da população escolar, já que a manutenção (ou não) de uma escola deverá ter em conta o número de alunos que estará em idade escolar até 2020, a possível evolução da população escolar, e às quais se deverá associar a análise da perda atual de alunos para outras escolas do território. Estes subcritérios apresentam níveis de ponderação que variam entre o 3 e 4 .

Um outro critério de análise introduzido na matriz foi o referente à dinâmica empresarial, embora com um nível de ponderação muito baixo (1) uma vez que, e apesar de poder influenciar as dinâmicas territoriais e as empresas possam ser excelentes atores para a concretização de parcerias, não parecem ser determinantes para o sucesso escolar de um aluno.

O quarto critério diz respeito à componente pedagógica (ponderação global de todos os subcritérios apresentam 25\%), surgindo aqui um número muito significativo de subcritérios, nomeadamente: notas obtidas pelos alunos, quer ao nível da avaliação contínua ao longo do ano letivo (ponderação 5), quer ao nível das notas de exame (ponderação 4); análise do ensino pré-escolar (ponderação 4); percurso escolar dos antigos alunos (ponderação 4); estratégias pedagógicas e de avaliação (ponderação 5; recursos pedagógicos (ponderação 4); atividades 
de enriquecimento e apoio curricular (ponderação 3); relação entre turmas e níveis de ensino (ponderação 3); escola e ciclos de ensino (ponderação 3); e, anteriormente referido, projeto educativo de escola (ponderação 5).

\begin{tabular}{|c|c|c|c|c|c|c|c|c|c|c|}
\hline \multirow[b]{3}{*}{ CRITERIOS } & \multirow[b]{3}{*}{ Subcritérios } & \multirow{2}{*}{\multicolumn{3}{|c|}{$\begin{array}{c}\text { Fator ponderaçāo } \\
\text { (de menos importante a } \\
\text { muito importante) }\end{array}$}} & \multirow{2}{*}{\multicolumn{5}{|c|}{$\begin{array}{c}\text { Avaliaçầo } \\
\text { (de menos relevante a } \\
\text { mais relevante) }\end{array}$}} & \multirow{3}{*}{ Resultado } \\
\hline & & & & & & & & & & \\
\hline & & \begin{tabular}{l|l}
1 & 2 \\
\end{tabular} & 3 & 4.5 & 1 & 2 & 3 & 4 & 5 & \\
\hline \multirow{4}{*}{ Espaço } & Distáncia-Tempo & & & & & & & & & \\
\hline & Sinuosidade & & & & & & & & & \\
\hline & ACP/contextos socioeconómicos territoriais & & & & & & & & & \\
\hline & Somatériu porcial & & & & & & & & & \\
\hline \multirow{4}{*}{ Demografia } & Populą̧äo Escolar (previsōes 2020-2021) & & & & & & & & & \\
\hline & $\begin{array}{l}\text { Proješ́es demográficas 2011-2021 (crescimento } \\
\text { positivo/nula/negativa) }\end{array}$ & & & & & & & & & \\
\hline & Fidelizaçăo da população escolar & & & & & & & & & \\
\hline & Somatorio porcial & & & & & & & & & \\
\hline \multirow{2}{*}{$\begin{array}{l}\text { Dinámica } \\
\text { Empresarial }\end{array}$} & Empresas & & & & & & & & & \\
\hline & Somatório parcial & & & & & & & & & \\
\hline \multirow{11}{*}{$\begin{array}{c}\text { Componentes } \\
\text { Pedagógica }\end{array}$} & Notas de Frequência $4^{9}$ ano & & & & & & & & & \\
\hline & Notas de Exame 4\% ano & & & & & & & & & \\
\hline & Pré-escolar & & & & & & & & & \\
\hline & Percurso escolar dos antigos alunos & & & & & & & & & \\
\hline & Estratégias pedagógicas e de avaliaçẫo & & & & & & & & & \\
\hline & Recursos pedagógicos & & & & & & & & & \\
\hline & Atividades de enriquecimento curnicular & & & & & & & & & \\
\hline & Turmas e niveis de ensino & & & & & & & & & \\
\hline & Escola e cidos de ensina & & & & & & & & & \\
\hline & Projeto Educativo da Escola & & & & & & & & & \\
\hline & Somatório porcial & & & & & & & & & \\
\hline \multirow{7}{*}{$\begin{array}{l}\text { Espaçoe } \\
\text { Comunidade } \\
\text { Educativa }\end{array}$} & Qualidade da infraestrutura escolar atual & & & & & & & & & \\
\hline & Custos de manutençâo do edifiç escolar atual & & & & & & & & & \\
\hline & Qualidade da infraestrutura escolar de acolhimento & & & & & & & & & \\
\hline & Recursos da Comunidade/Património & & & & & & & & & \\
\hline & Escola como espaço público & & & & & & & & & \\
\hline & Opiniăo dos pais sobre a escola & & & & & & & & & \\
\hline & Somatório parciai & & & & & & & & & \\
\hline & & & & & & & iomat & ório & & \\
\hline
\end{tabular}

Figura 1

Matriz de análise de escolas de baixa densidade

Por fim, o último critério diz respeito ao espaço e comunidade educativa (ponderação global de 10\%) em que é proposta a análise dos seguintes subcritérios: qualidade da infraestrutura escolar e os seus custos de manutenção (ponderação de 3 e 4, respetivamente); qualidade da infraestrutura escolar de 
acolhimento (ponderação de 4); comunidade e património (ponderação de 3); e os dois últimos, a escola como espaço público e a opinião dos pais sobre a escola (ambos com fatores de ponderação de 4).

Assim, e com base num pormenorizado diagnóstico que integrará análises diferenciadas (quantitativas, qualitativas e cartográficas), construir-se-á para cada escola em situação de risco de encerramento uma grelha de avaliação na qual será encontrado um valor referencial relativamente aos limiares que, entretanto, deverão vir a ser definidos e aceites pela tutela.

\section{Notas para reflexóes futuras}

Os estabelecimentos do $1 .^{\circ}$ ciclo (bem como os do pré-escolar) dos territórios rurais e de montanha no Portugal deste início do século xxI, caracterizam-se por genericamente terem poucos alunos, poucos recursos e se encontrarem inseridos em comunidades isoladas, resultado da desertificação e envelhecimento que caracterizam estes setores do território nacional. Segundo a tutela, estes factos constituíram-se como o principal obstáculo à modernização da escola do 1. ${ }^{\circ} \mathrm{CEB}$, situação que levou ao encerramento de largas centenas de escolas por todo o interior do país. Contudo, observam-se também argumentos que defendem a sua manutenção já que a escola em meio rural permite utilizar os conhecimentos existentes e desenvolver sinergias entre toda a comunidade educativa, utilizando a riqueza do espaço envolvente de modo a permitir às crianças passar do meio familiar para a escola sem rutura do contexto familiar, favorecendo as relaçóes entre indivíduos e facilitando uma construção do tecido social e afetivo.

A criação de uma Matriz para planeamento de rede em territórios de baixa densidade, e após uma década da implementação da reorganização, mesmo parecendo estranha, justifica-se plenamente neste momento. $\mathrm{O}$ seu objetivo fulcral é, assim, atinente à necessidade de preservar as débeis dinâmicas destes territórios, muito além do enfoque do limiar mínimo de alunos. A morfologia, a rede viária (distância-tempo e sinuosidade) e as dinâmicas demográficas 
(passadas, atuais e prospetivas), bem como os fatores de índole pedagógica e de comunidade envolvente nas quais a necessidade de desenvolver um projeto pedagógico diferenciador, foram assumidos na matriz como fatores decisivos no sucesso futuro desses jovens enquanto cidadáos.

\section{Referências bibliográficas}

Alcoforado, L.; Cordeiro, A. M. Rochette. \& Ferreira, S. (2012). A (re)organização da rede escolar como reflexo das transformaçōes demográficas, políticas e geográficas, nas últimas seis décadas em Portugal. In Mogarro, M.J. \& Cunha, M.T.S. (orgs.). Rituais, Espaços \& Patrimónios Escolares. IX Congresso Luso Brasileiro de História da Educação (Atas). Lisboa: Instituto de Educaçăo da Universidade de Lisboa, pp. 5423-5435.

Alcoforado, L; Cordeiro, A. M. Rochette \& Ferreira, A. Gomes (2014). Territórios, Comunidades Educadoras e Desenvolvimento Sustentável. In A. M. Rochette Cordeiro, Luís Alcoforado e A. Gomes Ferreira (Coords.), Territórios, Comunidades Educadoras e Desenvolvimento Sustentável. Coimbra: DG-FLUC, pp. 7-14.

Alpe, I. (2008). Les élèves ruraux sont-ils "défavorisés"? La construction et le traitement par les politiques éducatives d'une inégalité hypothétique. Colloque international "Efficacité \& Équité en Éducation Université Rennes 2, 19/20/21, pp. 3-13.

Alpe, I. (2012). Contexte territorial et organisation scolaire: l'école rurale française, de l'idéalisation à la stigmatisation. Revue suisse des sciences de l'éducation 34 (2).

Amiguinho, A (2005). Educação em meio rural e desenvolvimento local. Revista Portuguesa de Educação. 18(2), pp. 7-43.

Autès, Michel (2004). Três formas de desligadura. In Saul Karsz (org.), La Exclusión: Bordeando sus Fronteras. Definiciones y Matices. Barcelona: Gedisa, pp. 15-54.

Azevedo, José Maria (1996). Os Nós da Rede: O Problema das Escolas Primárias em Zonas Rurais. Porto, Ediçōes ASA. 176 p.

Boix, R. (2008). La politique éducative catalane et l'école rurale : équité et efficacité dans le territoire. Colloque international Efficacité \& Équité en Éducation. Université Rennes 2, 19/20/21, pp. 4-18.

Canario, R. (2000). A escola no mundo rural: contributos para a construção de um objecto de estudo. In Educação, Sociedade \& Culturas, n. ${ }^{\circ}$ 14, pp. 121-139.

Champollion, P. (2008). La territorialisation de l'école au regard de l'égalité des chances: frein ou levier? Éléments de cadrage et de réflexion développés principalement à partir des territoires ruraux isolés et montagnards. Colloque international Efficacité \& Équité en Éducation. Université Rennes 2, 19/20/21, pp. 19-31.

Champollion, P. (2011). «El impacto del territorio en la educación. El caso de la escuela en Francia." Profesorado - Revista de currículum y formación del profesorado, Vol. 15, N.o 2, pp. 53-69.

Cordeiro, A. M. Rochette (2014). O lugar dos Municípios no planeamento e gestáo da rede escolar em Portugal. In Maria de Lurdes Rodrigues (coord.), 40 anos de políticas de educação 
em Portugal: a construçâo do sistema democrático de ensino, Vol. II, Coimbra. Almedina, pp. 421-444.

Cordeiro, A. M. Rochette \& Alcoforado, L. (Coord.) (2015). Programa Intermunicipal de Prevenção do Abandono Escolar e Promoção da Igualdade de Acesso ao Ensino da Comunidade Intermunicipal Regiāo de Coimbra. Coimbra, DG-FLUC (Relatório Técnico - inédito).

Cordeiro, A. M. Rochette \& Gama, R. (coords.) (2015). Reorganização de rede escolar em Territórios de baixa densidade - Matriz de análise. Projeto Educativo Local do Fundão - Volume III. Coimbra, DG-FLUC,105 p. (Relatório Técnico - inédito).

Cordeiro, A. M. Rochette \& Martins, H. (2013). A Carta Educativa Municipal como instrumento estratégico de reorganização da rede educativa: tendências de mudança. Cadernos de Geografia, n. ${ }^{\circ} 32$, pp. 339-356.

Cordeiro, A. M. Rochette; Martins, H. \& Ferreira, A. Gomes (2014) As cartas educativas municipais e o reordenamento da rede escolar no Centro de Portugal: das condições demográficas às decisóes políticas. Revista Ensaio: aval. pol. públ. Educ., Set 2014, Vol.22, N.o 84, pp. 581-607, Rio de Janeiro.

Ferreira, F. \& Oliveira, J. (2007). Escola e Políticas Educativas: lugares incertos da criança e da cidadania. Perspectivas, Vol. 25, n. 1, jan./jun. Florianópolis, Brasil. pp. 127-148.

INE, I.P. (2012). Censos 2011, resultados definitivos - Regiáo Centro. Instituto Nacional de Estatística, Lisboa.

INE, I.P. (2014). Tipologia de Áreas Urbanas de 2014 (TIPAU 2014). Lisboa, Instituto Nacional de Estatística, I.P.

Jean, Yves (2003). Écoles rurales. Diversité sociale des structures scolaires et des politiques municipales. Ville-École-Intégration, Enjeux-Migrations-Formations, 134, pp. 112-128.

Justino, D.; Pascueiro, L.; Franco, L.; Santos, R.; Almeida, S. \& Batista, S. (2014). Atlas da Educação: Contextos sociais e locais do sucesso e insucesso - Portugal 1991/2012. Lisboa, CESNOVA.

Machado, F. (2013). A gestâo curricular em turmas com diferentes anos de escolaridade - conceçōes e práticas pedagógicas dos professores do 1. ${ }^{\circ} \mathrm{CEB}$. Dissertação de Mestrado em Estudos da Criança - Área de Especialização em Integração Curricular e Inovação Educativa. Instituto de Educação da Universidade do Minho, Portugal.

Matthews, P.; Klaver, E.; Lannert, J. Ó.; Concluain, G. \& Ventura, A. (2009). Política educativa para o primeiro ciclo do ensino básico. Avaliação internacional. Lisboa, Editorial do Ministério da Educação.

Mingat, A. \& Ogiet, C. (1995). Elementos para uma nova reflexão sobre a escola primária em meio rural. In R. Canário (Org.), Escola Rural na Europa Instituto das Comunidades Educativas. Cadernos ICE. pp. 13-31.

Nazareth, J. M. (1988). Princípios e Métodos de Análise da Demografia Portuguesa. Lisboa: Edições Presença.

Sigsworth, A \& Solstad, K. J. (2001). Making Small Schools: A Handbook for Teachers in Small Rural Schools. Addis Ababa: UNESCO, International Institute for capacity Building in Africa.

Smit, R. \& Humpert, W. (2012). Differentiated intruction in small schools. Teaching and Teacher Education, 28, Elsevier, Lda, pp. 1152-1162.

Zanten, A. van \& Obin, J.-P. (2008). La Carte Scolaire, Que sais-je, Paris: PUF, 127p. 